\title{
The ultrasonic motion detector: A conditioned stimulus for rats in the CER paradigm*
}

\author{
CHRISTOPHER L. CUNNINGHAM \\ University of Oregon Medical School, Portland, Oregon 97201
}

\begin{abstract}
In an attempt to resolve conflicting data concerning the conditioned-stimulus properties of the $40-\mathrm{kHz}$ signal generated by the ultrasonic motion detector, the high-frequency signal (96-112 dB) was used as the CS in a CER experiment. Rats receiving forward pairings of the tone with shock showed progressive decreases in activity in the presence of the tone as compared to controls during off-the-baseline conditioning sessions. During the CER test session, the forward-pairings group showed reliably more suppression to the high-frequency CS. It was concluded that the ultrasonic motion detector can mediate associative response tendencies.
\end{abstract}

The ultrasonic motion detector measures gross motor activity by sensing the changes that such activity produces in an ultrasonic field. It has been suggested that this device possesses several advantages over mechanical motion-detecting devices, namely, readily adjustable sensitivity, conveniently recorded digital output, and apparent unobtrusiveness (Peacock, Hodge, $\&$ Thomas, 1966; Peacock \& Williams, 1962). In support of this last contention, Peacock and Williams (1962) reported a failure to condition the rat's shuttlebox avoidance response to the $41 \mathrm{kHz}$ signal generated by their device. Moreover, after 100 paired presentations of the signal with a "painful" shock, they observed no conditioned pinna-reflex or changes in respiration and concluded that either their rats were not sensitive to the signal or that its intensity (which was not specified) was below the rat's threshold.

These data stand in marked contrast to the findings of several other studies involving either the motion detector itself or a tone similar in frequency to that produced by the detector. In an early study, Gould and Morgan (1941) reported that rats were able to learn a shock-avoidance response to a $40-\mathrm{kHz} \mathrm{CS}$ and suggested that the rat's sensitivity at $40 \mathrm{kHz}$ was as good, if not better, than its sensitivity below $14 \mathrm{kHz}$. In an investigation of the upper portion $(10-50 \mathrm{kHz})$ of the rat's audiogram using a special discriminative-operant procedure, Gourevitch and Hack (1966) concluded that the rat was most sensitive in a one-octave band in the vicinity of $40 \mathrm{kHz}$ (threshold at $3.5-11 \mathrm{~dB}$, re 0.0002 dyne $/ \mathrm{cm}^{2}$ ). Crowley, Hepp-Reymond, Tabowitz, and Palin (1965) similarly found peak

*This research was supported in part by National Institute of Mental Health Grants MH 11735-05 and MH 23607-02 to Judson S. Brown. The author wishes to thank D. C. Anderson and C. R. Crowell for their advice and assistance and especially $J$. S. Brown, who also sponsors this paper. M. Meikle of the Kresge Hearing Research Laboratory, University of Oregon Medical School, is also thanked for her assistance in calibrating the ultrasonic tone. Requests for reprints should be sent to the author at the Department of Medical Psychology, University of Oregon Medical School, Portland, Oregon 97201. sensitivity at $40 \mathrm{kHz}$ in a cochlear-microphonic study of the rat audiogram.

The foregoing studies certainly suggest that perhaps Peacock and Williams (1962) were incorrect in their original assertion as to the unobtrusiveness of the ultrasonic device. Several recent studies have provided additional data in this regard. In these studies, a commercially available version of the Peacock and Williams detector was used (manufactured by Alton Electronics). In the first experiment, while attempting to assess the effects of intense, unsignaled, inescapable shock (preshock) on subsequent shock-elicited fighting in rats, Anderson, Murcurio, and Mahoney (1970b) discovered that the presence of the ultrasonic tone during test sessions eliminated the attenuating effects of preshock on fighting behavior (cf. Payne, Anderson, \& Murcurio, 1970). In a subsequent study, Anderson, Cunningham, and Simons (1970a) examined the effect of the tone on the behavior of preshocked rats in a water-licking punishment situation, and reported that both preshock treatment and the tone (regardless of the preshock condition) intensified the effects of response-contingent shock. The tone did not affect licking rate per se, but appeared somehow to increase the adverse effects of shock. In a careful attempt to replicate and extend the findings of Anderson et al (1970a), Cunningham and Anderson (1974) again found an effect due to preshock, but were unable to demonstrate any effect of the tone. The reasons benind this discrepancy have yet to be ascertained.

It is perhaps quite obvious that no definitive statements can yet be made concerning the varied and paradoxical effects of the ultrasonic tone used in the preceding experiments. While the aforementioned studies of the rat's audiogram attest to the organism's ability to hear a $40-\mathrm{kHz}$ tone, there are virtually no studies which specifically have assessed the nature of its potential associative and/or motivational properties, especially at the intensity employed by ultrasonic motion detectors currently in use. The present 
experiment represents an initial attempt to examine some of these properties, in particular, to determine whether the tone can function as a conditioned stimulus (CS) for the rat in a classical-conditioning situation. Inasmuch as Peacock and Williams's (1962) failure to establish classically conditioned responses to an ultrasonic tone CS remains unchallenged, in the current experiments, the high-frequency output of the motion detector was used as the CS for establishing a conditioned emotional response (CER). By measuring the behavioral effects of superimposing the tone upon an operant baseline, presumably one should be able to assess the tone's ability to function as an elicitor of acquired response tendencies.

\section{METHOD}

\section{Subjects}

Sixteen naive, female albino rats, 100-120 days old were used (obtained from Carworth Farms, Portage, Michigan).

\section{Apparatus}

The chamber used for conditioning and testing was a Grason-Stadler operant box (Model E3125A). A stainless steel drinking tube mounted in a rubber washer was inserted through one of the aluminum ends of the chamber and was connected to one input terminal of a Lehigh Valley drinkometer (Model 1520). A Plexiglas partition shielded all but the rat's mouth and tongue from the tip of the drinking tube. The grid floor was connected to the input ground of the drinkometer.

The US was provided by a Grason-Stadler shock generator and scrambler (Model E1064GS) with shock intensity set to $1.6 \mathrm{~mA}$. The tone CS was the output of an Alton ultrasonic motion detector (Model 6). The transmitting and receiving transducers were mounted $5 \mathrm{~cm}$ apart at the center of the Plexiglas lid of the chamber. The audio signal was approximately sinusoidal, and its frequency, as determined by a Hewlett-Packard electronic counter (Model 5233L), was $40.2 \mathrm{kHz}$. Sound-pressure level was measured by a 0.25 -in. Bruel and Kjaer condenser microphone (Cartridge Type 4136, with protective grid removed) held at a 90-deg incidence to the transducer at various points within the sound field. A cloth toy rat was placed at the drinking tube during these measurments in order to approximate actual conditions. Readings ranged from 95 to $112 \mathrm{~dB}$, with small changes in the position of the microphone often resulting in large changes in intensity.

The receiving transducer of the motion detector was connected so as to permit movements to be recorded during conditioning and testing, and the device was adjusted to its maximum sensitivity. The operant chamber was housed in an IOTEK (Iowa City, Iowa) sound-attenuating chamber $(36 \times 34 \times 71 \mathrm{~cm}$, inside), which in turn was housed in a larger sound-shielded booth. The IOTEK chamber was illuminated by a 28-V, 6-W light bulb. Masking noice was provided by a speaker located behind the operant box on the same side as the drinking tube.

\section{Procedure}

On the first day of the experiment, all water bottles were removed, and on each of the next 2 days, each rat was allowed to drink water for $10 \mathrm{~min}$ in its home cage at the approximate time it would be run on succeeding days. On the third and fourth days of water deprivation, the rats received their 10-min water ration in the operant chamber. Twenty-four hours later, and on each of the succeeding 5 days, each animal was given two nonreinforced $30-\mathrm{sec}$ presentations of the ultrasonic tone while licking for water (for a total of 12 exposures).
Suppression-ratio measures and activity counts were recorded on each presentation.

Seventy-two hours later, the rats were randomly assigned to two groups (8 rats/group), and returned to the conditioning chamber for classical-conditioning trials. The drinking tube was removed, and the $6-\mathrm{W}$ lamp was extinguished. The first four trials during the initial conditioning session were $30-\mathrm{sec}$ presentations of the ultrasonic tone alone. For the FC group, these were followed by 10 pairings of the 30 -sec tone with a 2-sec, 1.6-mA shock, such that tone offset coincided with US onset. For the backward conditioning (BC) group, the order of presentation was reversed. US onset preceded tone onset by 10 sec. Each group received an additional 10 conditioning trials on the following day. The ITI averaged $60 \mathrm{sec}$ (range $=40$ to 80 sec). Activity counts during the 30 -sec CS were recorded on every trial.

On each of the following 2 days, the animals were placed in the operant chamber and allowed to begin licking. Ten seconds following the 60 th lick, a $30-\mathrm{sec}$ pretest period began, during which licks were counted. At the end of this interval, the tone was presented for $30 \mathrm{sec}$ while both licks and activity counts were recorded. The first lick following offset of the tone recycled the apparatus for a second test trial. Upon completion of the second trial, the rat was returned to its home cage.

\section{RESULTS}

\section{Activity}

Mean activity counts during the CS were calculated for every rat on each of the six preconditioning CS exposure days. A groups by days analysis of these scores showed no effects. An overall mean of 81 activity counts was measured during each CS presentation.

Variability in the activity data from the conditioning phase warranted the use of nonparametric analyses. Median motion counts during the four preconditioning (Pre-CS) trials were computed, as well as a median for each block of five conditioning trials. Figure 1 shows these data. A Mann-Whitney comparison indicated that there were no difference between groups on the pre-CS trials $(U=31, p>.05)$. Between-group comparisons made at the first and last blocks of conditioning revealed no difference at the first block $(U=31.5, p>.05)$, but a reliable difference during the last block $(U=11$, $\mathrm{p}<.05$ ). Wilcoxon tests comparing each group's first block with its last block indicated a significant decrease over training for the FC group $(T=0, p<.05)$, but not for the $\mathrm{BC}$ group $(\mathrm{T}=14, \mathrm{p}>.05)$. A test contrasting the pre-CS block with the first conditioning block (collapsed over groups) showed a reliable overall decrease in movement in the presence of the ultrasonic tone following the introduction of shock to the conditioning situation $(T=3, p<.05)$.

A days by groups analysis of variance was also applied to the daily mean motion counts during test presentations of the ultrasonic tone. No significant effects were obtained, although $\mathrm{FC}$ rats tended to show less movement (mean counts: $\mathrm{FC}=87, \mathrm{BC}=96$ ).

\section{Licking}

There were no initial differences between groups either in terms of percent body weight loss or mean 


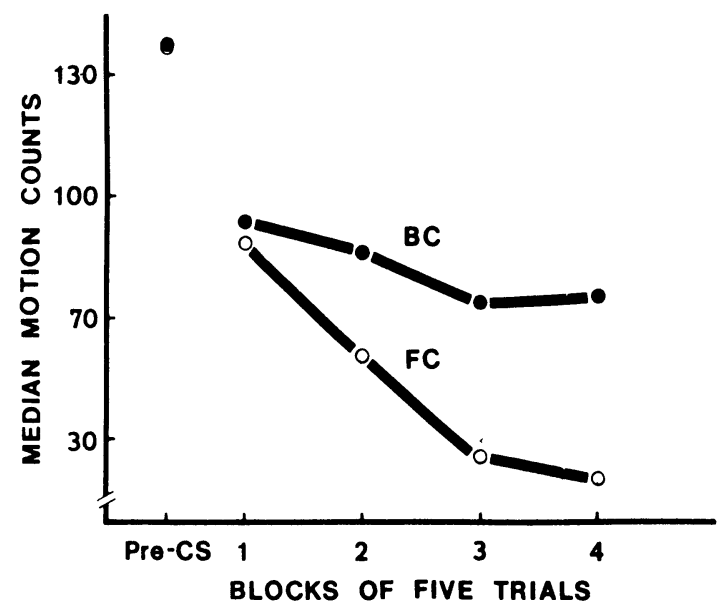

Fig. 1. Median number of motion counts during preconditioning exposures (Pre-CS) to the ultrasonic CS and during successive five-trial conditioning blocks for forward (FC) and backward (BC) conditioning groups.

number of licks during the preconditioning drinking sessions (ps $>.05$ ). A mean suppression ratio (cf. Annau $\&$ Kamin, 1961) was calculated for every rat on each of the 6 days during the preconditioning CS-exposure phase. The mean suppression was 0.38 on Day 1 and 0.47 on Day 6. An overall groups by days analysis of variance yielded a significant effect of days $[F(5,90)=6.15, p<.05]$, but no differences between groups. A similar analysis of mean first-lick latencies following CS offset during this phase showed no reliable effects (ps $>.05$ ). On the average, the first lick occurred within $1.1 \mathrm{sec}$ of CS offset.

The test suppression ratios are shown in Fig. 2. An overall between-within analysis of variance was applied to these data and revealed effects of groups $[\mathrm{F}(1,14)=22.5]$, days $[\mathrm{F}(1,14)=31.79]$, trials $[\mathrm{F}(1,14)=8.4]$, groups by days $[\mathrm{F}(1,14)=10.2]$, and groups by trials $[\mathrm{F}(1,14)=16.8$; all ps $<.05]$.

The mean latency to the first lick following CS offset was computed for each rat over test days. A groups by days analysis of these scores indicated a significant days effect $[F(1,14)=12.8]$ and Days by Groups interaction $[F(1,14)=4.6 ;$ both ps <.05]. A between-groups comparison on Day 1 showed that FC animals were reliably slower to resume licking $(36 \mathrm{sec})$ than were $\mathrm{BC}$ animals $(11.7 \mathrm{sec})[\mathrm{F}(1,14)=4.87, \mathrm{p}<.05]$. On Day 2 , the mean latencies were nearly identical $(2.7 \mathrm{sec}$ vs $3.4 \mathrm{sec})$.

\section{DISCUSSION}

An attempt was made in this experiment to determine whether the $40-\mathrm{kHz}$ output of the ultrasonic motion detector can function as a CS in the CER paradigm. During an off-the-baseline conditioning phase, rats receiving forward pairings of the tone with shock showed progressive decreases in activity in the presence of the tone as compared to controls.
While these data might suggest that the tone is an effective CS, an equally plausible interpretation can be made in terms of nonassociative mechanisms which do not appeal to the presence of the tone or its paired relation to shock (e.g., a decay in the arousing aftereffects of shock on activity as a function of time following shock).

The licking data, on the other hand, clearly suggest that the ultrasonic signal functions as a conditioned stimulus for the rat. An on-the-baseline preconditioning CS-exposure phase indicated that the tone initially exerted only a moderate inhibitory effect upon licking, and this effect dissipated with repeated exposures. Testing subsequent to the conditioning phase, however, revealed reliable group differences in terms of both response suppression and latency to the first response following CS off set, suggesting that the tone had acquired the ability to elicit an emotiqnal and/or skeletal-motor response.

Peacock and Williams's (1962) failure to establish conditioned responses to the signal produced by their device may reflect the relative insensitivity of the measures they chose to record, or it may be that the sound-pressure-level of their tone was below the rat's threshold. Nonetheless, at least one commercially available motion detector generates a tone which can function as a CS for the rat. Thus, as a component of the total stimulus complex in any given situation, the tone (or its absence) might well elicit competing or facilitating responses, or produce stimulus-generalization decrement, external inhibition disinhibition, or dishabituation during successive phase of an experiment. The problems posed by the studies of Anderson et al $(1970 \mathrm{a}, \mathrm{b})$, however, remain to be resolved.

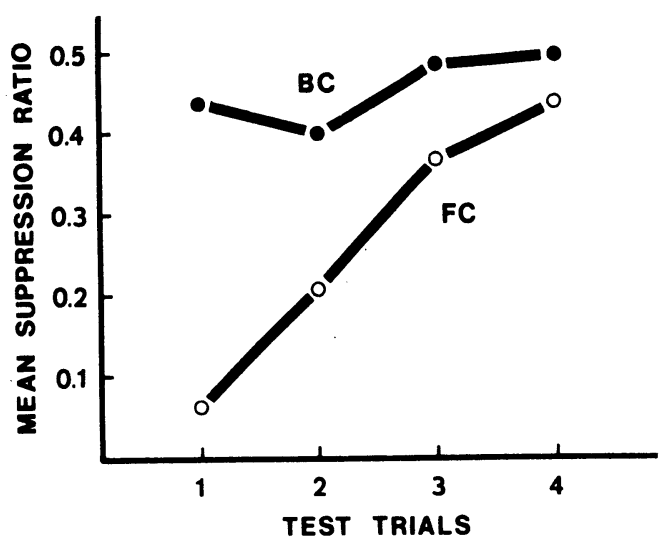

Fig. 2. Mean suppression ratio over test trials for forward (FC) and backward (BC) conditioning groups.

\section{REFERENCES}

Anderson, D. C. Cunningham, C., \& Simons, R. Intensification of passive-avoidance learning as a function of preshock and a 39-k Hz tone. Proceedings, 78th Annual Convention, APA 1970a, 247-248.

Anderson, D. C., Murcurio, J., \& Mahoney, P. Inhibition of preshock-produced reflexive fighting by a $39-\mathrm{kHz}$ tone. Physiology \& Behavior, 1970b, 5, 577-581.

Annau, Z., \& Kamin, L. J. The conditioned emotional response as a function of intensity of the US. Journal of Comparative \& Physiological Psychology, 1961, 54, 428-432.

Crowley, D. E., Hepp-R eymond, M., Tabowitz, D., \& Palin, J. Cochlear potentials in the albino rat. Journal of Auditory R esearch, 1965, 5, 307-316.

Cunningham, C., \& Anderson, D. C. The effects of a 39-k Hz tone on passive-avoidance learning in preshocked rats: A failure to replicate. Bulletin of the Psychonomic Society, 1974, 3 121-122. 
Gould, J. \& Morgan, C. T. Auditory sensitivity in the rat. Journal of Comparative \& Physiological Psychology, 1942, 34 321-329.

Gourevitch, G., \& Hack, M. H. Audibility in the rat. Journal of Comparative \& Physiological Psychology, 1966, 62, 289-291.

Payne, R., Anderson, D. C., \& Murcurio, J. Preshock-produced alterations in pain-elicited fighting. Journal of Comparative \& Physiological Psychology, 1970, 71, 258-266.
Peacock, L. J., Hodge, M. H., \& Thomas, R. K. Ultrasonic measurement and automatic analysis of general activity in the rat. Journal of Comparative \& Physiological Psychology, $1966,62,284-288$.

Peacock, L. J., \& Williams, M. An ultrasonic device for recording activity. American Journal of Psychology, 1962, 75, 648-652.

(R eceived for publication July $19,1974$. 